\title{
Cardiac magnetic resonance imaging in today's economic climate; a cost effectiveness analysis
} \author{
Ronald B Williams', Robert Biederman ${ }^{1}$ \\ From 2011 SCMR/Euro CMR Joint Scientific Sessions \\ Nice, France. 3-6 February 2011
}

Vinayak A Hegde ${ }^{\text {* }}$, J Ronald Mikolich', Mark Doyle', Vikas K Rathi ${ }^{2}$ June A Yamrozik',

\section{Introduction}

In the face of the current health care crisis, significant concerns have been raised about the independent clinical utilities of various cardiac imaging modalities. Particularly, Cardiac Magnetic Resonance (CMR) has been labeled "an expensive pretty picture" by some clinicians as compared to other diagnostic modalities.

\section{Purpose}

Aim

We hypothesized that results of CMR would independently impact patient management in a cost effective manner.

\section{Study design}

Observational study.

\section{Methods}

We retrospectively reviewed charts of 361 patients (pts) undergoing CMR exams for a variety of indications at two centers in Western Pennsylvania. While Center 1 was an academic center, Center 2 was a private community hospital. Patient outcomes were assessed and the costs of ordering CMR were compared against the benefits to see if CMR indeed resulted in health care savings.

\section{Results}

Of the 361 studies, a significant impact was observed in 256 (71\%) pts based on CMR results. Of these, 69 (27\%) pts received a new diagnosis. Additionally, CMR results avoided invasive procedures in 38 pts and prevented layered testing in 26 pts. Translating these results in to cost benefit analysis, there was a total benefit of

${ }^{1}$ Allegheny General Hospital, Pittsburgh, PA, USA

Full list of author information is available at the end of the article
$\$ 1248,939$ and a total loss of $\$ 415,902$, indicating net savings of $\$ 833,037$ for the study group as a whole (see Figure 1). The most savings were observed in pts who received a new diagnosis such as tumor not thrombus, sarcoid not ARVD or benign mass not cancer, and the least, in the routine follow up of clinically stable patients with vascular pathologies such as aneurysms, dissections or pulmonary vein imaging post ablation for atrial fibrillation.

\section{Conclusions}

CMR, when appropriately ordered, independently contributes to patient management, and triggers a major impact on therapeutic decisions in a cost effective manner. As an autonomous diagnostic modality, CMR prevents layered testing and serves a gate keeping function, highlighting the prudent use of cost effective technology.

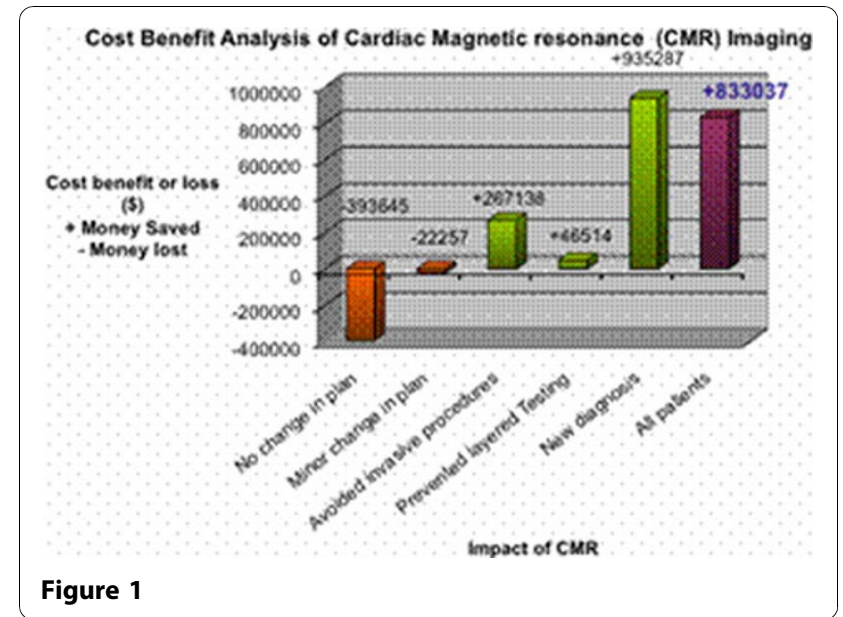




\title{
Author details
}

${ }^{1}$ Allegheny General Hospital, Pittsburgh, PA, USA. ${ }^{2}$ Bon Secours Heart and

Vascular Institute, Richmond, VA, USA.

Published: 2 February 2011

\begin{abstract}
doi:10.1186/1532-429X-13-S1-M12
Cite this article as: Hegde et al:: Cardiac magnetic resonance imaging in

today's economic climate; a cost effectiveness analysis. Journal of

Cardiovascular Magnetic Resonance 2011 13(Suppl 1):M12.
\end{abstract}

Submit your next manuscript to BioMed Central and take full advantage of:

- Convenient online submission

- Thorough peer review

- No space constraints or color figure charges

- Immediate publication on acceptance

- Inclusion in PubMed, CAS, Scopus and Google Scholar

- Research which is freely available for redistribution

Submit your manuscript at www.biomedcentral.com/submit

O) BioMed Central 